\title{
Prevalence of Helicobacter pylori in patients with gall stones before and after cholecystectomy: a longitudinal study
}

\author{
N A Abu Farsakh, E Roweily, M Steitieh, R Butchoun, B Khalil
}

\begin{abstract}
Fifty six patients with gall stones were enrolled in this study to assess the presence of Helicobacter pylori in gastric mucosa before and after cholecystectomy. Samples were taken from gastric juice and antral mucosa through endoscopy performed on these patients before and after the operation. Gastric juice was examined for bile salt concentration as an indicator of duodenogastric reflux. Antral mucosa was studied for the presence of $H$ pylori and inflammatory response. Duodenogastric reflux was significantly increased $(\mathbf{p}<0.001)$ and $H$ pylori significantly decreased $(p<0.01)$ in the postoperative period. Mucosal inflammation and its activity were less in the postoperative period but the differences did not reach statistically significant values.

(Gut 1995; 36: 675-678)
\end{abstract}

Keywords: Helicobacter pylori, cholecystectomy, gall stones.

Since its culture by Marshall et al in $1982,^{1}$ Helicobacter pylori has been found in gastric biopsy specimens and linked to many diseases in the gastrointestinal tract. It has been isolated from patients with duodenal ulcers in $80-100 \%$, from type B gastritis in $70-90 \%$, in gastric ulcers $58-86 \%$, in atrophic gastritis $43-89 \%$, in non-ulcer dyspepsia in $43-87 \%$, and in patients with gastric carcinoma in $19-80 \%{ }^{2-10}$ After gastric operations prevalence of $H$ pylori ranged from $26-40 \%$. This decreased frequency after gastric operations was attributed to increased concentration of bile salts in gastric juice resulting from increased duodenogastric reflux in these patients. ${ }^{11} 12$ In asymptomatic normal populations, rates of isolation of $H$ pylori were between $13-87 \%$, increasing in frequency with advancing age. ${ }^{13-17}$ In Jordanians, studies showed a prevalence of $70 \%$ in patients with acute gastritis, $73 \%$ in chronic gastritis, and $83 \%$ in patients with duodenal ulcers. ${ }^{18}$

Patients with gall stones may be asymptomatic or may complain of biliary colic. Presence of various dyspeptic manifestations in patients with gall stones was found to be similar to their prevalence in the general population ${ }^{1920}$ although few studies suggest an association between both disorders. ${ }^{2122}$ Relief of these dyspeptic manifestations occasionally occur after cholecystectomy while others may show persistence of their symptoms or even may develop dyspepsia after cholecystectomy; the postcholecystectomy syndrome. ${ }^{23} 24$ Is there a link between $H$ pylori and gall stone disease? To our knowledge prevalence of $H$ pylori has not been assessed in patients with gall stones or in postcholecystectomy patients and its relation to dyspepsia in this group of patients has not been studied. In this study we tried to assess prevalence of $H$ pylori in these patients, which may be important for the better understanding of dyspeptic manifestations in this group.

\section{Methods}

\section{Patient group}

Fifty six patients (48 women and eight men), who were diagnosed to have gall stones by ultrasonography at Princess Basma Teaching Hospital in Irbid, northern Jordan, were included in this study. Age range was 22-70 years with a median age of 44 . Patients who were included had no previous gastric surgery and no history of serious medical illness. They were evaluated before the operation and 3-30 months postoperatively by gastroscopy, biopsy, and bile salt determination in gastric juice.

\section{Gastroscopy and biopsies}

Upper gastrointestinal endoscopy was performed after an overnight fast. Antral mucosal biopsy specimens were taken using sterilised biopsy forceps. Specimens were always taken from an area of intact mucosa within $5 \mathrm{~cm}$ from the pylorus and sent for histopathological and microbiological examination.

\section{Histopathological examination}

Three to five samples were fixed in $10 \%$ formalin, embedded in paraffin wax, and stained with haematoxylin and eosin. $H$ pylori was identified by morphology and labelled as either present or absent accordingly. Antral mucosa was assessed for the presence of inflammation, which was reported to be present if inflammatory cells were seen in the mucosa. The inflammation was assessed to be acute when polymorphs were seen in the lamina propria or intraepithelially, or both. ${ }^{325-27}$

\section{Microbiological examination}

One to two samples were aseptically transported into a sterile pijou bottle containing 
TABLE I Results of $\mathrm{H}$ pylori isolation, presence of inflammation, and gastric bile salt concentration in 56 patients with gall stones before operation

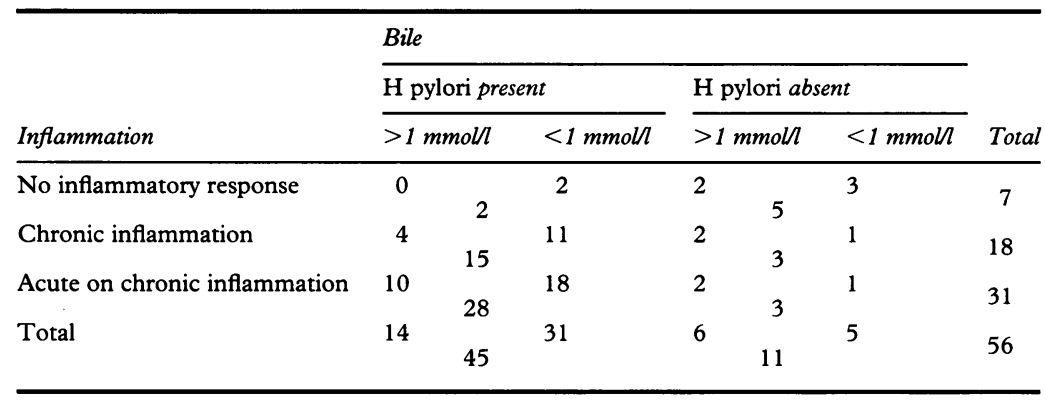

$5 \mathrm{ml}$ of sterile brain heart infusion broth (Difco Lab, Detroit, USA), cultured on blood agar plates (Difco), and incubated at $37^{\circ} \mathrm{C}$ under microaerophilic conditions for 7-14 days. Developing colonies were identified as $H$ pylori based on colonic morphology, Gram stain, production of catalase, oxidase, and urease. ${ }^{28}$

Bile salt determination

Five $\mathrm{ml}$ of fasting gastric juice were taken during endoscopy for determination of bile salts using thin layer chromatography and a purified $3 \alpha$ hydroxysteriod dehydrogenase. ${ }^{29}$

Statistical analysis

McNemar's test was used for statistical analysis of dependent data.

\section{Results}

Bacteriological and histological evaluation to study $H$ pylori before and after operation (112 samples) was carried out in these 56 patients as described. In 102 samples, both results were identical, a concordance rate of $91 \%$. Results in 10 samples were discordant, three were negative by histopathology and seven were negative by bacteriological examination. All discordant results were considered positive.

Before operation, 45 of 56 patients were positive for $H$ pylori ( $80 \%$ ), while in 11 patients $H$ pylori was not identified $(20 \%)$. After cholecystectomy, nine further patients were cleared of $H$ pylori, increasing the total number who were negative for $H$ pylori to 20 of 56 patients $(36 \%)(\mathrm{p}<0 \cdot 01)$.

Inflammation was seen in the antral mucosa in 49 patients ( $88 \%$ of total) before the operation, 43 of them were $H$ pylori positive. Inflammation was reported to be acute in 31

TABLE II Results of $\mathrm{H}$ pylori isolation, presence of inflammation, and gastric bile salt concentration in 56 patients with gall stones after operation

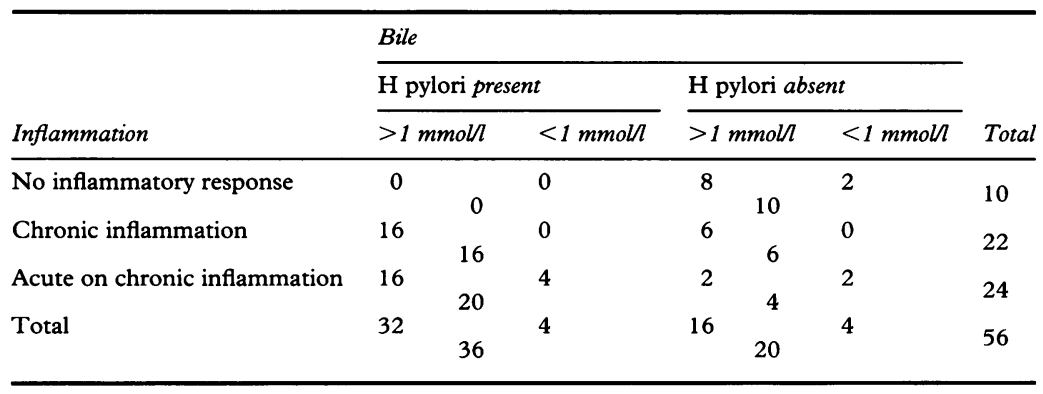

patients $(55 \%$ of total), 28 were $H$ pylori positive. After cholecystectomy, 46 patients showed inflammation, 24 of $46(43 \%)$ showed acute inflammation, these results were not statistically significant $(p>0.05)$.

Bile salt concentration in the fasting gastric juice was reported to be higher than $1 \mathrm{mmol} / \mathrm{l}$ in 20 patients before operation $(36 \%)$, while after cholecystectomy, 28 more patients showed increase in their bile concentration to more than $1 \mathrm{mmol} / \mathrm{l}$, raising the total number with high bile concentration to 48 patients ( $86 \%$ of total). This result is highly significant $(p<0.001)$. Of these 28 patients who showed a rise in their bile concentration, nine patients were positive for $H$ pylori before operation but cleared the bacteria after operation (32\%).

Tables I and II show details of the findings before and after operation.

\section{Discussion}

$H$ pylori has been clearly shown in many studies to be associated aetiologically to chronic type B histological antral gastritis, characterised by polymorphs and mononuclear cells infiltrating the superficial epithelium and the lamina propria. ${ }^{25} 30$ Bile salts were shown to cause a different type of gastritis, the enterogastric reflux gastropathy; which is characterised histologically by paucity of inflammatory cells in the lamina propria. This type of gastritis was reported in most patients after vagotomy or gastrojejunostomy. Prevalence of $H$ pylori was much lower in this alkaline reflux compared with its high prevalence in type B antral gastritis. ${ }^{21} 32$ Reflux of bile was reported to decrease the recovery of $H$ pylori from gastric specimens. Although in vitro studies have suggested an inhibitory effect for bile salts on $H$ pylori growth, their exact role in vivo needs to be evaluated further. ${ }^{33} 34$

In our study, it was clearly shown that duodenogastric reflux was considerably increased in postcholecystectomy patients compared with their preoperative status: $36 \%$ in preoperative patients compared with $86 \%$ postoperatively as evidenced by increased bile salt concentration above $1 \mathrm{mmol} / 1 \quad(\mathrm{p}<0.001)$. $H$ pylori was identified either histologically or microbiologically in 45 of $56(80 \%)$ in patients with gall stones. Postoperatively, $H$ pylori was identified in 36 of 56 patients $(64 \%)$. This decrease, which is statistically significant $(\mathrm{p}<0.01)$, can be explained by the higher concentration of bile salts or other unrecognised factor(s) present in or caused by the refluxed juice, affecting colonisation of $H$ pylori in the gastric epithelium.

The decrease in $H$ pylori colonisation in the gastric mucosa was reflected histologically by decrease in the components of acute inflammation as evidenced by polymorph infiltration in the lamina propria or intraepithelium, or both, which was present in 29 patients preoperatively versus 20 in the postoperative period. Total number of patients who showed inflammatory response also dropped from 32 preoperatively to 24 patients in the postoperative period but this difference did not reach statistically 
significant values. Patients who had $H$ pylori without inflammatory response in gastric mucosa cleared the bacteria postoperatively. These results showed that colonisation of $H$ pylori in gastric epithelium is directly related to the activity of inflammation in the antral mucosa, and both were inversely related to the concentration of bile salts in gastric juice.

Although the relation between gall stones and dyspeptic manifestations is mostly an association of two common disorders, evidence exists in published reports that suggests that some patients with dyspepsia and gall stones are affected favourably after cholecystectomy, ${ }^{22} 35$ while others show persistence of their symptoms or develop new symptoms after the operation. The last two groups are considered part of what is labelled as the postcholecystectomy syndrome. ${ }^{23} 24$

Is the increase in duodenogastric reflux and the change in bile acid concentration in gastric juice with the consequent fall in $H$ pylori colonisation related to this change in dyspepsia? To answer this question, several points should be considered. Firstly, bile salts in the stomach were shown to cause alkaline gastritis, which may cause certain symptoms like burning epigastric pain, bilious vomiting, episodic nausea, and vomiting. ${ }^{36} 37$ Installation of intestinal contents into the residual gastric pouch produced similar symptoms supporting a role for the refluxed bile in their production. ${ }^{38}$ Secondly, the amount of refluxed material is crucial to the development of these symptoms, and this may account for the development of these symptoms in some patients while they are absent in most patients. ${ }^{36} 38$ Thirdly, in several studies, the concentration of bile salts in the fasting gastric juice was found to be proportional to the net bile acid reflux per hour. So assessment of bile salt concentration at endoscopy can represent the degree of duodenogastric reflux during 24 hours. ${ }^{37}{ }^{39}$ Fourthly, $H$ pylori is strongly associated with type $\mathrm{B}$ gastritis causing occasionally symptoms like epigastric fullness, heartburn, nausea, and vomiting. Although these symptoms are non-specific, there is some evidence that $H$ pylori related gastritis may cause them. 4679

Accordingly, we can assume that, at least in some patients who develop dyspepsia after cholecystectomy, their symptoms are caused by increased duodenogastric reflux and alkaline gastritis. In others the amount of bile reflux may not be high enough to cause this type of gastritis but is sufficient to affect $H$ pylori colonisation in the stomach. This may 'cure' $H$ pylori related gastritis with improvement in symptoms.

To confirm this assumption we suggest that additional studies are done on the symptoms present in patients with gall stone disease before and after cholecystectomy, and the relation of this change in symptoms, if present, to the amount of bile reflux and $H$ pylori in the stomach. If such a relation is established, it may help in the treatment of patients who have residual dyspepsia or develop new dyspeptic manifestations after cholecystectomy. ${ }^{40} 41$
In conclusion, our study shows that duodenogastric reflux is considerably increased, and $H$ pylori colonisation in gastric mucosa is decreased after cholecystectomy. If gastritis should conclusively be shown to cause dyspepsia, then these findings would help explain changes in the pattern of symptoms after cholecystectomy, and suggest lines of treatment in this group of patients.

1 Marshall BJ, Warren JR. Unidentified curved bacilli in the stomach of patients with gastritis and peptic ulceration. Lancet 1984; i: 1311-5.

2 Marshall BJ, McGechie DB, Rogers PA, Glancy RJ. Campylobacter infection and gastroduodenal disease. Med $\mathcal{F}$ Austr 1985; 142: 439-44.

3 Pettross CW, Appleman MD, Cohen H, Valenzuela JE, Chandrasoma P. Prevalence of Campylobacter pylori and association with antral mucosal histology in subjects with and without upper gastrointestinal symptoms. Dig Dis $S c i$ 1988; 33: 649-53.

4 Gutlerrez D, Sierra F, Gomez MC, Camargo H. Campylobacter pylori in chronic environmental gastritis and duodenal ulcer patients. Gastroenterology 1988; 94: and du.

5 Fiocca R, Villani L, Turpini R, Salcia E. High incidence of Campylobacter-like organisms in endoscopic biopsies from patients with gastritis with or without peptic ulcer. Digestion 1987; 38: 234-44.

6 Goodwin CS, Armstrong JA, Marshall BJ. Campylobacter pyloridis, gastritis and peptic ulceration. $f$ Clin Pathol 1986; 39: 353-65.

7 Rauws EAJ, Langenberg W, Houthoff HJ. Campylobacter pyloridis-associated chronic active antral gastritis; a prospective study of its prevalence and the effects of prospective study of its prevalence and the effects of
antibacterial and antiulcer treatment. Gastroenterology 1988; 94: 33-40

8 Price AB, Levi J, Dolby JM. Campylobacter pyloridis in peptic ulcer disease: microbiology, pathology and scanning electron microscopy. Gut 1985; 21: 1183-8.

9 Buck GE, Gourley WK, Lee WK, Subramanyan K, Latimer JM, Di Nuzzo AR. Relation of Campylobacter pyloridis to gastritis and peptic ulcer. F Infect Dis 1986; 153: 664-9.

10 Feng Y, Wang Y. Campylobacter pylori in patients with gastritis, peptic ulcer and carcinoma of the stomach in Lanzhou, China [letter]. Lancet 1988; i: 1055.

11 O'Connor HJ, Dixon MF, Wyatt JI, Axon ATR, Ward DC Dewar EP, et al. Effect of duodenal ulcer surgery and enterogastric reflux on Campylobacter pyloridis. Lancet 1986; ii: $1178-81$.

12 Campos RR, Mompean JAL, Parcicio PP, Lopez JB. Role of Helicobacter pylori infection and duodenogastric reflux in the pathogenesis of alkaline reflux gastritis after gastric operations. Surg Gynecol Obstet 1993; 176: 594-8.

13 Jones DM, Eldridge J, Fox AJ, Sethi P, Whorwell PJ. Antibody to the gastric campylobacter-like organisms (Campylobacter pyloridis). Clinical correlations and distribution in the normal population. $f$ Med Microbiol 1986; 22: $57-62$.

14 Rawles JW, Paull G, Yardley JH, Hendrix TR, Ravich WJ, Walters LL, et al. Gastric Campylobacter-like organisms Walters LL, et al. Gastric Campylobacter-like organisms
(CLO) in a US hospital population [abstract]. (CLO) in a US hospital

15 Graham DY, Malaty HM, Evans DG, Evans DJ, Klein PD, Adam E. Epidemiology of Helicobacter pylori in an asymptomatic population in the United States. Effect of age, race, and socioeconomic status. Gastroenterology 1991; 100: 1495-501

16 Rashed RS, Ayoola EA, Mofleh IA, Chowdhury MN, Mahmood K, Faleh FZ. Helicobacter pylori and dyspepsia in Arab population. Trop Geogr Med 1992; 44: 304-7.

17 Katelaris PH, Tippett GH, Norbu P, Lowew DG, Brennan R, Farthing MJ. Dyspepsia, Helicobacter pylori, and peptic ulcer in a randomly selected population in India. Gut tic ulcer in a randomi

18 Latif AH, Shami SK, Batchoun R, Murad N, Sartawi O. Helicobacter Pylori: a Jordanian study. Postgrad Med $\mathcal{f}$ 1991; 67: 994-8.

19 Glambek I, Arnesjo B, Soreide O. Correlation between gallstones and abdominal symptoms in a random population. Results from a screening study. Scand $\mathcal{f}$ Gastroenterol 1989; 24: 277-81.

20 Diehl AK. Symptoms in gallstone disease. Baillieres Clin Gastroenterol 1992; 6: 635-57.

21 Gunn A, Keddie N. Some clinical observations on patients with gall stones. Lancet 1972; ii: 7771-3.

22 Kingston RD, Windsor CWO. Flatulent dyspepsia in patients with gallstones undergoing cholecystectomy. $B r \mathcal{F}$ Surg 1975; 62: 231-3.

23 Ros E, Zambon D. Postcholecystectomy symptoms. A prospective study of gall stone patients before and two prospective study of gall stone patients befo

24 Lasson A. The postcholecystectomy syndrome: diagnostic and therapeutic strategy. Scand $\mathcal{F}$ Gastroenterol 1987; 22: 897-902.

25 Graham DY. Campylobacter pylori and peptic ulcer disease. Gastroenterology 1989; 96: 615-25.

26 Steer HW. The gastroduodenal epithelium in peptic ulceration. $\mathcal{F}$ Pathol 1985; 146: 355-62. 
27 Wyat JI, Rathbone BJ, Heatley RV. Local immune response to gastric campylobacter in non-ulcer dyspepsia. $\mathcal{F}$ Clin Pathol 1986; 38: 863-70.

28 Goodwin CS, Blincow ED, Warren JR, Waters TE, Sanderson CR, Easton L. Evaluation of cultural techniques for isolating Campylobacter pyloridis for endoscopic biopsies of gastric mucosa. 7 Clin Pathol 1985; 38: 1127-31.

29 Fausa O, Skalhegg BA. Quantitative determination of bile acids and their conjugates using thin layer chromatocids and a purified $a$ hyd Scand $\mathcal{F}$ Gastroenterol 1974; 9: 248-54.

30 Karttunen T, Niemela S. Campylobacter pylori and duodenogastric reflux in peptic ulcer disease and gastritis. denogastric reflux in peptic ulcer disease and gastritis.

Lancet 1988; i: 118 .

1 Stein HJ, Smyrk TC, DeMeester TR, Rouse J, Hinter RA Clinical value of endoscopy and histology in the diagnosis of duodenogastric reflux disease. Surgery 1992; 112: 796-804

32 Sobala GM, O'Connor HJ, Dewa EP, King RF, Axon AT, Dixon MF. Bile reflux and intestinal metaplasia in grastic mucosa. F Clin Pathol 1993; 46: 235-40.

33 Tompkins DS, West AP. Campylobacter pylori, acid, and bile [letter]. F Clin Pathol 1987; 40: 1387.

34 Graham DY. Bile acid therapy for Helicobacter pylori [letter]. Aliment Pharmacol Ther 1992; 6: 653.
35 Paul A, Troidl H, Gay K, Viell B, Bode C. Dyspepsie und Nahrungsmittelunvertraglichkeitein beim symptomatischen Gallensteinleiden. Hilft die Cholecystektomie? Chirurg 1991; 62: 462-6.

36 Hoare AM, McLeish A, Thompson H, Alexander-Williams J. Selection of patients for bile diversion surgery: use of bile-acid measurement in fasting gastric aspirates. Gut 1978; 19: 163-5.

37 Ritchie WP Jr. Alkaline reflux gastritis: an objective assessment of its diagnosis and treatment. Ann Surg 1980; 192: 288-98.

38 Meshkinpour H, Marks JW, Schoenfield LJ, Bonnoris GG Carter S. Reflux gastritis syndrome: mechanism of sympCarter S. Reflux gastritis syndrome: mechar
toms. Gastroenterology 1980; 97: 1283-7.

39 Ludwig S, Ippoliti A. Objective evaluation of symptomatic bile reflux after antrectomy. Gastroenterology 1975; 68: 699-707.

40 Buch KL, Weinstein WM, Hill TA, Eleshoff JD, Reedy TJ, Tippoliti AF, et al. Sucralfate therapy in patients with symptoms of alkaline reflux gastritis. Am $\mathcal{F}$ Med 1985; 79 (suppl 25): 49-54

41 Nicolai JJ, Speelman P, Tytgat GN, van der Stadt J. Comparison of the combination of cholestyramine/ alginate with placebo in the treatment of post gastrectomy 